\title{
Clostridium difficile toxin A induces a specific antisecretory factor which protects against intestinal mucosal damage
}

\author{
J Torres, E Jennische, S Lange, I Lönnroth
}

\begin{abstract}
Peroral challenge with toxin A from Clostridium difficile induced the formation of antisecretory factor in rats. The animals were given $100 \mu \mathrm{g}$ of the toxin, which was followed by a pronounced diarrhoea and by the appearance of antisecretory factor in the pituitary gland. In electrofocusing, the induced antisecretory factor separated in two peaks (pI 5.4 and 5.0); both fractions showed a lectin-like binding to agarose. The pI 5.4 fraction inhibited cholera toxin as well as toxin $A$ induced fluid secretion, while pI 5.0 inhibited toxin $A$ induced secretion only. Immunohistochemistry showed that an antisecretory factor of pI 5.0 protected the mucosa from the cytotoxic effect of toxin A, but did not affect the binding of toxin $A$ to the intestinal epithelium. Sodium dodecylsulphate-polyacrylamide gel electrophoresis of the $\mathrm{pI} 5.0$ protein showed two major fractions to be present, one of molecular weight $60 \mathrm{kDa}$, the other of $30 \mathrm{kDa}$, the latter probably being a degradation product of the former.
\end{abstract}

Clostridium difficile is commonly the agent responsible for antibiotic associated diarrhoea, colitis, and pseudomembranous colitis in humans. ${ }^{12}$ The antibiotic depresses the bacterial flora which normally counteract extended colonisation by $C$ difficile in the gut. ${ }^{34}$ The pathogenic effects of $C$ difficile are probably mediated by exotoxins, the two most important being toxin $\mathrm{A}$ and toxin B. ${ }^{56}$ Toxin $A$ is an enterotoxin, responsible for haemorrhagic fluid accumulation in intestinal loops of rats, rabbits, and hamsters..$^{7-9}$ Toxin A also causes elongation of ovary cells in Chinese hamsters, an effect similar to that of enterotoxins from Vibrio cholerae, Escherichia coli, and Campylobacter jejuni. ${ }^{10}$ Toxin B induces intestinal secretion without any apparent damage to the intestinal mucosa. ${ }^{11}$

Colonisation with $C$ difficile toxigenic strains during treatment with antibiotics might occur, however, without any clinical sign of intestinal disease. ${ }^{12}$ Intestinal resistance to this pathological challenge is probably mediated by a variety of defence mechanisms, including those triggered by immunocomponent cells. Recently, a new protein was reported which counteracts the in vivo secretory action of the enterotoxins from $V$ cholerae, $E$ coli, and $C j e j u n i .{ }^{13}{ }^{14}$ This protein was designated antisecretory factor, owing to its capacity to inhibit intestinal fluid secretion. It is mainly synthesised in the central nervous system and is secreted from the pituitary gland into the blood, milk, and bile. ${ }^{15}{ }^{16}$ In young animals there is normally no production of antisecretory factor, but after intestinal challenge with enterotoxin production is induced in the central nervous system. Antisecretory factor from pigs consists of one peptide chain with a molecular mass of 60 $\mathrm{kDa} .{ }^{17}$ It attaches with high affinity to galactosecontaining polysaccharides such as agarose, but is dissociated again by elution with galactose or methyl $\alpha$-D-glucoside.

In contrast to the enterotoxins from $V$ cholerae and $E$ coli, toxin $\mathrm{A}$ from $C$ difficile causes intestinal hypersecretion in combination with extensive destruction of the mucosa. It was therefore important to investigate whether this toxin induced a similar formation of antisecretory factor as that induced after hypersecretion caused by the non-tissue damaging enterotoxins.

\section{Methods}

TOXIN A

C difficile strain CCUG 19126 (VPI 10463, obtained from D M Lyerly/T D Wilkins, VPI Blacksburg, USA) was used for production of toxin $A$. The toxin was produced and purified to homogeneity as previously described..$^{18}$ Rabbit antiserum against toxin $\mathrm{A}$ was obtained as previously described, ${ }^{18}$ and the IgG fraction isolated according to Steinbuch and Audren. ${ }^{19}$

\section{PERORAL CHALLENGE}

Sprague-Dawley rats, 2-3 months old, were used for induction of the antisecretory activity. Under ether anaesthesia animals were challenged perorally via a baby feeding tube with $100 \mu \mathrm{g}$ of toxin $\mathrm{A}$ in $3 \mathrm{ml}$ of a $6 \%$ bicarbonate solution. After some eight hours all animals had pronounced diarrhoea (wet tail). After 16 hours the rats were sacrificed and their pituitary glands removed.

\section{EXTRACTION AND PURIFICATION OF}

\section{ANTISECRETORY FACTOR}

Fifteen rats were challenged perorally with toxin A for induction of antisecretory factor. After 16 hours the pituitary glands were removed and immediately placed in ice cold $145 \mathrm{mM} \mathrm{NaCl}, 50$

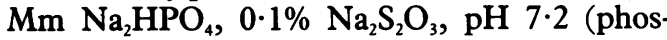
phate buffered saline with sodium thiosulphide, PBST), homogenised with a loose fitting glass homogeniser, and centrifuged at $27000 \times g$ for 10 minutes. The clear supernatant was run in a preparative isoelectrofocusing column with a linear sucrose gradient. ${ }^{20}$ Ampholine (LKB), $\mathrm{pH}$ $3 \cdot 5-10$ or 4-6, was used as the carrier electrolyte; the anode solution was $0.1 \mathrm{M}$ glutamic acid, 0.5 $M$ phosphoric acid and the cathode solution 


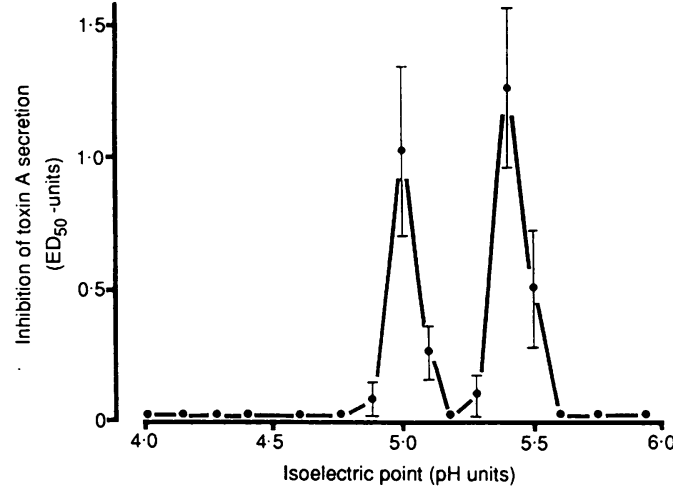

Figure 1: Isoelectric focusing of toxin $A$ induced antisecretory proteins. Pituitary gland homogenates were run in a preparative isoelectric focusing with ampholine $(L K B) p H$ 4-6.

was $0.01 \mathrm{M} \beta$-alanine, $0.5 \mathrm{M}$ ethanolamine. Fractions were asayed for $\mathrm{pH}$ and dialysed against PBST for 48 hours and then tested for antisecretory activity. The samples with antisecretory activity were applied to a $5 \mathrm{ml}$ Sepharose 6B (Pharmacia) column to separate them according to their affinity to agarose. ${ }^{17}$ The column was washed with PBST and then eluted stepwise with $0.1 \mathrm{M}, 0.3 \mathrm{M}, 0.9 \mathrm{M}$, and $1.5 \mathrm{M}$ methyl- $\alpha$-D-glucoside (Sigma) in PBST. The eluates were dialysed against PBST before measuring the antisecretory activity.

\section{POLYACRYLAMIDE ELECTROPHORESIS}

Fractions with antisecretory activity were concentrated to a final $50 \mu$ l volume in a minicon B15 concentrator (Amicon). Concentrated samples were analysed in precast gradient gel electrophoresis, run in the presence of sodium dodecylsulphate in accordance with the manufacturer's instructions (Pharmacia). Electrophoresis was performed in a $2-16 \%$ gradient gel in $0.04 \mathrm{M}$ Tris, $0.02 \mathrm{M}$ sodium acetate, $0.002 \mathrm{M}$ ethylenediamine tetra-acetate, $0.2 \%$ sodium dodecylsulphate, $0 \cdot 1 \%$ sodium thiosulphate, $\mathrm{pH} 7 \cdot 4$. The test and reference proteins were incubated in $1.75 \%$ sodium dodecylsulphate, $0.3 \%$ glycerol, and $0.1 \mathrm{M} \mathrm{NaH}_{2} \mathrm{PO}_{4}, \mathrm{pH} 7 \cdot 0$, at $53^{\circ} \mathrm{C}$ for 15 minutes. The test sample was applied to four adjacent wells. After electrophoresis reference proteins were stained with $0 \cdot 1 \%$ Coomassie brilliant blue. The portion of the gel with the four samples of antisecretory factor was cut in $0.5-1 \cdot 5$ $\mathrm{cm}$ pieces, from which the proteins were eluted by dialysis against PBST for three days. After dialysis each fraction was tested for antisecretory activity.

\section{ANTISECRETORY ACTIVITY}

The different fractions were tested for antisecretory activity in rats. ${ }^{1121}$ Toxin A 0.5 and $1.5 \mu \mathrm{g}$ or cholera toxin 1 and $3 \mu \mathrm{g}$ were injected into two adjacent $15 \mathrm{~cm}$ ligated intestinal loops with a total volume of $1 \mathrm{ml}$ each. The test sample or buffer control at a final volume of $2 \mathrm{ml}$ was injected via the penis vein one minute before toxin $\mathrm{A}$ challenge. Each recipient rat received a fraction of a sample equivalent to the total amount obtained from one donor (the content of one pituitary gland). After six hours the fluid secretion of the test loop $(\mathrm{mg} / \mathrm{cm})$ was estimated by subtracting the weight and length of the control loop from that of the test loop. One $\mathrm{ED}_{50}$ of the antisecretory activity was defined as the dose causing $50 \%$ inhibition of the fluid secretion compared with untreated control animals. Antiserum against purified antisecretory factor from pig pituitary gland ${ }^{17}$ was tested for its capacity to neutralise the various preparations of antisecretory factor from rat. The antiserum was added to the samples in the proportion 1:20. After incubation for 30 minutes at $23^{\circ} \mathrm{C}$ the solution was tested for antisecretory activity.

\section{MORPHOLOGY}

Mucosal structure

Samples with antisecretory activity eluted after isoelectric focusing were pooled to study their effect on the intestinal mucosal damage caused by toxin $\mathrm{A}$. They were administered intravenously one minute before the injection of $1 \cdot 5$ $\mu \mathrm{g}$ of toxin A into the ligated loops. After one, four, and six hours the rats were fixed in vivo (under ether anaesthesia) by transcardial perfusion with $40-60 \mathrm{ml}$ ice cold $4 \%$ paraformaldehyde in phosphate buffered saline. The middle portion of the loop was cut into $5 \mathrm{~mm}$ pieces which were immediately placed in the same fixative. These were then embedded into methacrylate plastic (Historesin) and $l \mu \mathrm{m}$ thick sections prepared using a Historange microtome (LKB). The sections were either stained with basic fuchsin/methylene blue/Azur III or with periodic acid-Schiff/haematoxylin using standard procedures.

\section{Binding of toxin $A$}

The effect of antisecretory factor on the binding of toxin A to the intestinal epithelium was studied. Samples of antisecretory factor were administered intravenously before toxin A challenge. One intestinal loop was prepared per animal and injected with $3 \mu \mathrm{g}$ of toxin A. After one and two hours the rats were perfused in vivo with the $4 \%$ paraformaldehyde/phosphate buffered saline fixative; the loop was taken out and cut in $5 \mathrm{~mm}$ pieces, which were then placed in the same fixative. After postfixation for three hours the specimens were rinsed overnight in phosphate buffered saline containing $7 \cdot 5 \%$ sucrose, and then frozen in liquid nitrogen.

TABLE I The effect of toxin $A$ induced antisecretory factor $(A S F)$ on intestinal fluid response to toxin $A$ and cholera toxin

\begin{tabular}{lcc}
\hline & \multicolumn{2}{l}{$\begin{array}{l}\text { Inhibition of fluid secretion, } E D_{\mathrm{s},} \text {, after } \\
\text { intestinal challenge with }\end{array}$} \\
\cline { 2 - 3 } ASF fraction & Toxin A & Cholera toxin \\
\hline pI 5.4 & $1 \cdot 1$ & 0.8 \\
$\quad+$ anti-ASF & $<0.1$ & $<0.1$ \\
pI 5.0 & 1.6 & \\
$\quad+$ anti-ASF & 1.1 &
\end{tabular}

*The values represent the mean of the response in two rats. Two loops were prepared in each animal and challenged with either 0.5 and $1.5 \mu \mathrm{g}$ of toxin $A$ or 1 and $3 \mu \mathrm{g}$ of cholera toxin. ASF was inoculated intravenously as described in the text. For calculation of $\mathrm{ED}_{s_{0}}$ see Methods. 
TABLE II Elution of antisecretory factor (ASF) from agarose gel with methyl $\alpha$-D-glucoside

\begin{tabular}{lll}
\hline & \multicolumn{2}{l}{$\begin{array}{l}\text { Inhibition of toxin A induced fluid } \\
\text { secretion, } E D_{\text {so }^{\star}} \text { : }\end{array}$} \\
\cline { 2 - 3 } $\begin{array}{ll}\text { Elution with methyl } \\
\text { a-D-glycoside (molll) }\end{array}$ & Fraction pI 5.4 & Fraction pI 5.0 \\
\hline 0.0 & $<0.1$ & $<0.1$ \\
0.1 & 0.5 & 0.9 \\
0.9 & 1.1 & $<0.1$ \\
1.5 & 1.0 & $<0.1$ \\
\hline
\end{tabular}

«The values represent the mean of the response in two rats. Two loops were prepared in each animal and challenged with 0.5 and $1.5 \mu \mathrm{g}$ of toxin A. For calculation of $\mathrm{ED}_{s_{0}}$ see Methods.

Cryostat sections $(6 \mu \mathrm{m})$ were prepared and incubated for 12 hours with antibodies against toxin $\mathrm{A}$ at $4^{\circ} \mathrm{C}$, followed by the secondary antibodies (anti-rabbit Ig, peroxidase-linked species specific $F\left(a^{\prime}\right)$ fragment from donkey, Amersham, UK) for two hours at room temperature. Bound horseradish peroxidase was visualised by the 3,3-diaminobenzidine reaction. Control sections were incubated without the primary antibodies or with antibodies preabsorbed with an excess of toxin $A$.

\section{Results}

INDUCTION OF ANTISECRETORY FACTOR

Peroral administration of $100 \mu \mathrm{g}$ of toxin A caused a pronounced diarrhoea (wet tail) in the rat 8-10 hours after challenge. The diarrhoea decreased after 16 hours, abundant antisecretory factor activity then being found in the pituitary gland. The extracted antisecretory factor from one such gland inhibited $93(10) \%$ (mean (SEM)) of the secretion induced by toxin $A$, corresponding to a dose of $1.8 \mathrm{ED}_{50}$.

\section{PURIFICATION AND CHARACTERISATION OF} ANTISECRETORY FACTOR

The antisecretory factor activity present in the pituitary gland was purified and characterised. Preliminary electrofocusing using ampholine pH 3.5-10 showed that the activity focused between $\mathrm{pH} 5 \cdot 0$ and 6.0. Ampholine $\mathrm{pH} 4-6$ was then used for better resolution. In this gradient the activity focused in two peaks, one corresponding to pI $5 \cdot 0$ and the other to $\mathrm{pI} 5 \cdot 4$ (Fig 1 ). The fraction pI 5.4 inhibited toxin A and cholera toxin-induced secretion, while the fraction pI 5.0 counteracted secretion induced by toxin $\mathrm{A}$ but not that induced by cholera toxin (Table I). Antiserum against porcine antisecretory factor abolished the activity of fraction pI $5 \cdot 4$, but not that of fraction pI 5.0 (Table I). Both fractions attached to agarose gel with high affinity and dissociated again in a gradient of methyl $\alpha-D$ glucoside. Antisecretory factor of pI $5 \cdot 0$, however, dissociated with a $0 \cdot 1 \mathrm{M}$ concentration of the sugar, while that of pI 5.4 mainly dissociated at a concentration of $0.9-1.5 \mathrm{M}$ (Table II).

The pI 5.0 fraction (specific for toxin A) was further characterised. It was run in sodium dodecylsulphate-polyacrylamide gel electrophoresis to estimate its molecular size. The antisecretory activity migrated in two peaks, the main peak corresponding to an approximate molecular size of $60 \mathrm{kDa}$ and the minor peak to
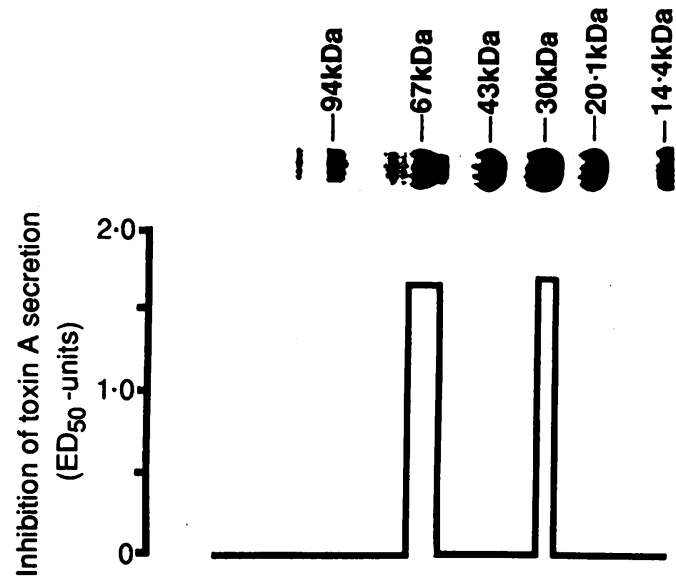

Figure 2: Estimation of the molecular size of the toxin induced $p I 5.0$ antisecretory protein. The $p I 5.0$ antisecretory factor was run in 2-16\% polyacrylamide gel electrophoresis gradient gel. The track with the reference proteins was stained, whereas the tracks with samples were sliced and the protein eluted by dialysis. Dialysates were then tested for inhibition of toxin $A$ induced secretion in small intestina loops. The activity migrated at two positions corresponding to $a$ size of $60 \mathrm{kDa}$ and $28 \mathrm{kDa}$ respectively.

about $30 \mathrm{kDa}$ compared with the migration of the protein markers (Fig 2).

\section{MORPHOLOGY}

Immunohistochemistry was used to study binding of toxin A to the mucosa of the small intestine in loops challenged with toxin for 60 minutes. In control animals not treated with antisecretory factor, binding of toxin A could be shown in the microvilli region of enterocytes on the villi (Fig 3A). No binding of the toxin to epithelial cells in the crypts was evident. Treatment of the animals with antisecretory factor did not affect the binding of the toxin to the mucosa, since a binding pattern similar to the control was seen (Fig 3B). Six hours after injection of toxin A extensive damage to the mucosa was seen in control animals (Fig 3C). In contrast, in rats treated with antisecretory factor the mucosa was well protected from the destructive effects of toxin A (Fig 3D). In these protected animals some shedding of epithelial cells from the upper parts of the villi was observed, but otherwise the morphology was fairly well preserved. There was no evidence of haemorrhage in the intestinal wall.

\section{Discussion}

The formation of antisecretory factor in rats after a challenge with cholera toxin has been clearly shown. ${ }^{1317}$ The results from previous studies implied that antisecretory factor was released as a response to the hypersecretion rather than as a response to the causative toxin. In contrast to these non-tissue damaging enterotoxins, toxin $\mathrm{A}$ from $C$ difficile induces two kinds of antisecretory factor in the pituitary gland of rats, one of pI 5.4 and one of pI 5.0.

Antisecretory factor with a pI of 5.4 inhibited fluid secretion in the small intestine, both that induced by cholera toxin and that induced by 


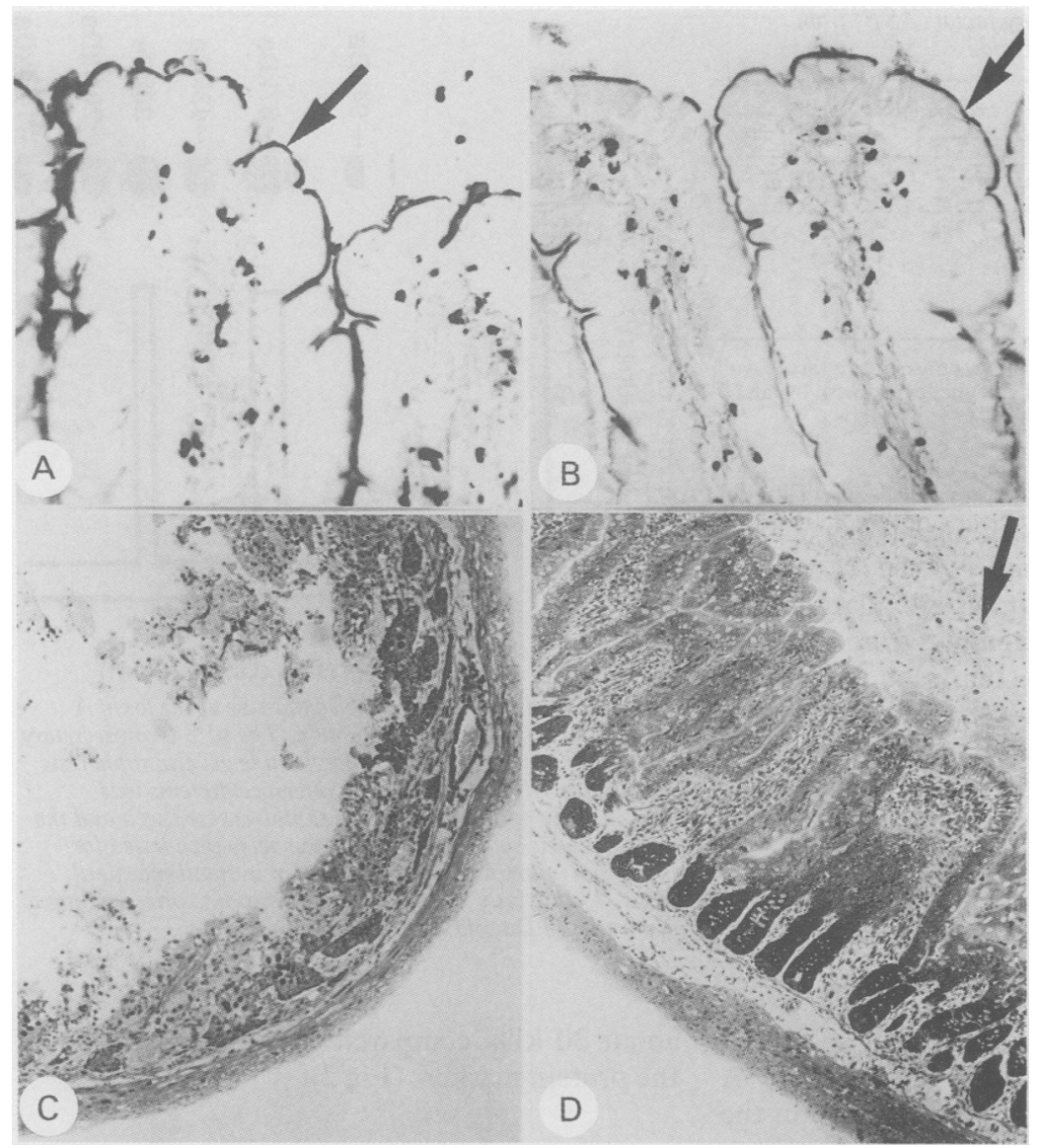

Figure 3: $(A, B)$ Cryostat sections from small intestinal loops exposed to toxin $A$ for one hour and showing toxin $A$ immunoreactivity, visualised by a horseradish peroxidase-conjugated secondary antibody. $(A)$ Control animal; $(B)$ animal pretreated with antisecretory factor. $B$ inding of toxin $A$ is evident in the microvilli region of villus enterocytes (arrows). (Original magnification $\times 350$. $)(C, D)$ Plastic sections showing the morphology of loops exposed to toxin A for six hours. $(C)$ Control animal; $(D)$ animal pretreated with antisecretory factor (arrow indicates shed epithelial cells). In the control animal there is extensive damage to the mucosa. (Original magnification $\times 100$.)

toxin A. The activity seemed to be similar to that of pig antisecretory factor which inhibits the secretory effects of several different enterotoxins. ${ }^{14}$ An antisecretory factor of pI $5 \cdot 4$ was also neutralised by antiserum against porcine antisecretory factor, which suggests that these two proteins are antigenically related.

An antisecretory factor of pI 5.0, however, differed from the antisecretory factor proteins previously described; it did not reverse cholera toxin induced secretion, but had a pronounced inhibitory effect on toxin A induced secretion. These results suggest that an antisecretory factor of pI 5.0 interferes with a reaction specific to toxin $\mathrm{A}$. The reaction probably takes place in the intestinal epithelial cells since toxin A induced destruction of these cells was counteracted by the pI 5.0 protein. This protein might have been formed in response to the destruction of the epithelial cells or in response to the local inflammatory reaction.

Toxin A seems to attach by receptors containing the trisaccharide Gal $\alpha 1-3 \mathrm{Gal} \beta 1-4 \mathrm{GlcNac} .{ }^{12} \mathrm{~A}$ possible target for antisecretory factor might be the binding of the toxin to the receptors on the intestinal epithelium. Immunohistological studies, however, did not show any blockage of toxin A binding to the epithelium by the pI 5.0 protein. This finding suggests that no direct interaction occurs between the antisecretory factor protein and toxin $A$ and agrees with earlier results concerning binding of cholera toxin and its inducible antisecretory factor..$^{1314}$ None the less, antisecretory factor might have affected the binding function by modifying the receptor or its mobility in the membrane.

Toxin A induced antisecretory factor, both of pI 5.0 and of 5.4 , bound spontaneously to agarose gel and was dissociated again in a gradient of methyl- $\alpha$-D-glucoside. This lectinlike binding also occurs in antisecretory factor proteins induced by hyperosmotic solutions of sugars or amino acids. ${ }^{20}$ These proteins are also similar in their intestinal effect and molecular weight but differ both in isoelectric point and in their reactions with antibodies. Furthermore, agarose bound antisecretory factor proteins vary in their dissociation constant when a gradient of methyl- $\alpha$-D-glucoside is applied. The differences in dissociation constant might reflect a variation in specificity in receptor binding as well as differences in specificity in their interference with enterotoxic activities.

In sodium dodecylsulphate-polyacrylamide gel electrophoresis, the pI 5.0 factor migrated in two peaks, one representing a molecular weight of about $60 \mathrm{kDa}$, the other of $30 \mathrm{kDa}$. Similar results were previously achieved in experiments with porcine antisecretory factor, where we concluded that the $30 \mathrm{kDa}$ protein is a degradation product. ${ }^{122}$ Thus the pI 5.0 protein probably consists of one peptide chain of molecular weight of $50 \mathrm{kDa}$ which is degraded by proteolytic enzymes into smaller peptides during tissue homogenisation and purification procedures.

Immunity to $\mathrm{C}$ difficile disease through vaccines has proved difficult to induce. ${ }^{2324}$ The newly discovered antisecretory factor proteins seem to be a promising alternative for the control of diarrhoeal diseases. Moreover, the present results suggest that these proteins have a potential capacity to control toxin induced tissue damaging intestinal disorders.

Financial support was provided by the Swedish Medical Research Council (grant No 7481), the Torsten and Ragnar Söderbergh Foundation, the Tore Nilsson Foundation, the Magnus Bergvall Foundation, and the Faculty of Medicine, Gothenburgh University.

1 Bartlett JG. Antibiotic-associated pseudomembranous colitis. Rev Infect Dis 1979; 1:530-9.

2 Gerding DN, Olson MM, Peterson LR, et al. Clostridium difficile-associated diarrhea and colitis in adults. Arch Intern Med 1986; 146: 95-100.

3 Lusk RH, Fekety R, Silva J, Browne RA, Rigler DH, Abrams GD. Clindamycin-induced enterocolitis in hamsters. $\mathcal{F}$ Infect Dis 1978; 137: 464-75.

4 Wilson KH, Silva J, Fekety FR. Suppression of Clostridium difficile by normal hamster flora and prevention of antibioticassociated caecitis. Infect Immun 1981; 34: 28.

5 Bartlett JG, Onkerdonk AB, Cisneros RL, Kasper DL. Clindamycin-associated colitis due to a toxin-producing species of Clostridium in hamsters. F Infect Dis 1977; 136: s01-5.

6 Rifkin GD, Silva J, Fekety FR, Sack RB. Antibiotic-induced colitis. Implication of a toxin neutralised by Clostridium sordellii antitoxin. Lancet 1977; ii: 1103-6.

7 Banno Y, Kobayashi T, Kono H, Watanabe K, Ueno K, Nozawa $Y$. Biochemical characterization and biologic actions of two toxins (D-1 and D-2) from Clostridium difficile. Rev Infect Dis 1984; 6: 11-20.

8 Lyerly DM, Lockwood DE, Richardson SH, Wilkins TD. Biological activities of toxins A and B of Clostridium difficile. Infect Immun 1982; 35: 1147-50.

9 Torres JF, Lönnroth I. Comparison of methods for the production and purification of toxin A from Clostridium difficile. FEMS Microbiol Lett 1988; 52:41-6.

10 Katoh T, Higaki M, Honda T, Miwatani T. Cytotonic effect of Clostridium difficile enterotoxin on Chinese hamster ovary cells. FEMS Microbiol Lett 1986; 34: 241-4.

11 Torres J, Jennische E, Lange S, Lönnroth I. Enterotoxins 
from Clostridium difficile; diarrhoeogenic potency and morphological effects in the rat intestine. Gut 1990; 31 : 7815.

12 Lyerly DM, Krivan HC, Wilkins TD. Clostridium difficile: its disease and toxins. Clin Microbiol Rev 1988; 1: 1-18.

13 Lange S, Lönnroth I. Passive transfer of protection agains cholera toxin in rat intestine. FEMS Microbiol Lett 1984; 24 165-8.

14 Lönnroth I, Lange S, Skadhauge E. The antisecretory factors: inducible proteins which modulate secretion in the small intestine. Comput Biochem Physiol 1988; 90A: 611-7.

15 Lange S, Lönnroth I. Bile and milk from cholera toxin treated rats contain a hormone-like factor which inhibits diarrhea induced by the toxin. Int Arch Allergy Appl Immunol 1986; 79: $270-5$.

16 Lönnroth I, Martinsson K, Lange S. Evidence of protection against diarrhoea in suckling piglets by a hormone-like protein in the sow's milk. $\mathcal{F}$ Vet Med 1988; 35: 628-35.

17 Lönnroth I, Lange S. Purification and characterization of the antisecretory factor: a protein in the central nervous system and in the gut which inhibits intestinal hypersecretion induced by cholera toxin. Biochim Biophys Acta 1986; 883: $138-44$
18 Torres JF, Lönnroth I. Production, purification and characterization of Clostridium difficile toxic proteins different from toxin A and from toxin B. Biochim Biophys Acta 1989; 998: $152-7$

19 Steinbuch M, Audren R. The isolation of IgG from mammalian sera with the aid of caprylic acid. Arch Biochem Biophys 1969; 134: 279-84

20 Lönnroth I, Lange S. Intake of monosaccharides or amino acids induces pituitary gland synthesis of proteins regulating intestinal fluid transport. Biochim Biophys Acta 1987; 925: 117-23.

21 Lange S. A rat model for an in vivo assay of enterotoxic diarrhea. FEMS Microbiol Lett 1982; 15: 239-42.

22 Lönnroth I, Lange S. Purification and characterization of a hormone-like factor which inhibits cholera secretion. FEBS hormone-like factor whic

$23 \mathrm{Kim}$ PH, Iaconis JP, Rolfe RD. Immunization of adult hamsters against Clostridium difficile associated ileocecitis and transfer of protection to infant hamsters. Infect Immun 1987; 55: 2984-92.

24 Fernie DS, Thompson RO, Batty I, Walker PD. Active and passive immunization to protect against antibiotic-associated caecitis in hamsters. Dev Biol Stand 1983; 53: 325-32. 